\title{
LOS PRINCIPIOS DE APLICACIÓN DE LOS DERECHOS EN LA CONSTITUCIÓN ECUATORIANA: UNA MIRADA DESDE LA DOCTRINA Y LA JURISPRUDENCIA
}

THE PRINCIPLES OF IMPLEMENTATION OF RIGHTS IN THE ECUADORIAN CONSTITUTION: A VIEW FROM THE DOCTRINE AND JURISPRUDENCE

\section{Esteban Javier Polo Pazmiño*}

Resumen: La doctrina especializada en el país, ha estudiado profundamente varios de los derechos reconocidos en nuestro sistema jurídico; no obstante, el desarrollo acerca de los principios que viabilizan el ejercicio de tales derechos, continúa siendo limitado. Este trabajo, precisamente, tiene como propósito examinar los denominados principios de aplicación de los derechos, a fin de comprender adecuadamente su objeto y utilidad en el modelo constitucional vigente. Dentro de la Constitución ecuatoriana, estos principios fueron previstos a manera de postulados rectores y transversales destinados a generar las condiciones normativas y de interpretación necesarias, para que los derechos sean plenamente ejercidos y, de ser el caso, protegidos y reparados. A través de este ensayo, se analizará el contenido y el alcance de todos los principios de aplicación de los derechos reconocidos en la Constitución ecuatoriana, desde una perspectiva doctrinaria y jurisprudencial, lo cual evidenciará la forma en que han sido concebidos desde el foro académico y en la práctica jurisdiccional. Este trabajo examinará, inicialmente, la noción de los principios jurídicos y de los principios de aplicación en particular, para, posteriormente, abordar cada uno de los postulados previstos en el artículo 11 de la Constitución. Su estudio permitirá tener un panorama general que, de ninguna manera,

\footnotetext{
* Profesor de la Universidad Andina Simón Bolívar, Quito (Ecuador). Candidato a Doctor en Derecho y Máster en Derecho Constitucional, Universidad de Castilla La Mancha, Toledo (España). Especialista Superior en Derecho Constitucional, Universidad Andina Simón Bolívar. Licenciado en Ciencias Jurídicas y Abogado por la Pontificia Universidad Católica del Ecuador. estebanpolo88@gmail.com
} 
pretende agotar el debate ni imponer el contenido de cada principio, sino reflexionar sobre su conceptualización por parte de cierto sector doctrinario y jurisprudencial.

Palabras clave: Principios, derechos, garantías, dignidad humana, constitucionalismo ecuatoriano

Abstract: The specialized doctrine in the country has deeply studied several of the rights recognized in our legal system; however, the development of the principles which render viable the exercise of such rights, remains limited. This work, precisely, aims to examine the so-called principles of application of the rights, in order to properly understand the purpose and usefulness in the current constitutional model. Within the Ecuadorian Constitution, these principles were foreseen as guiding and transversal postulates destined to create the conditions necessary policy and interpretation, for which the rights are fully exercised and, if applicable, protected and repaired. Through this essay, the content and scope of all the principles of application of the rights recognized in the Ecuadorian Constitution will be analyzed, from a doctrinal and jurisprudential perspective, which is evidenced by the manner in which they have been designed from the academic forum and in the practice of the courts. This paper will initially examine, on a general overview, the legal principles and the particular application principles, in order to subsequently address each of the postulates included on the 11th article of the Constitution. Its study will allow to have a general prospect that, in no way, tries to exhaust the debate nor to impose the content of each principle, but to reflect on its conceptualization from a particular doctrinal and jurisprudential sector's perspective.

Keywords: Principles, Rights, Guarantees, Human Dignity, Ecuadorian Constitutionalism

Sumario. I. Introducción. II. Los principios como normas jurídicas. III. Principios de aplicación y derechos. IV. Principios de aplicación de los derechos en la constitución ecuatoriana. IV.1. Titularidad de los derechos. IV.2. Exigibilidad de los derechos. IV.3. Principio de igualdad y no discriminación. IV.4. Aplicación directa de los derechos. VI.5. Principio de no restricción del contenido de los derechos. IV.6. Principio de favorabilidad o pro homine. IV.7. Características de los derechos. IV.8. Fuentes de los derechos. IV.9. Principio del desarrollo progresivo y no regresividad de los derechos. IV.10. El Estado frente a los derechos. V. Conclusiones. Referencias. 


\section{INTRODUCCIÓN}

La Constitución del Ecuador reconoce desde el año 2008 una serie de mecanismos hermenéuticos a los que les asigna la categoría de principios de aplicación. Tal como sugiere su denominación, estos principios son aquellos preceptos constitucionales que determinan la forma en que han de ejercerse e interpretarse los derechos; por lo que, su establecimiento responde a la necesidad de crear una base normativa que favorezca y facilite la aplicación idónea y eficaz de los derechos.

$\mathrm{Si}$ bien es cierto que el actual texto constitucional presenta un novedoso y desarrollado conjunto de principios de aplicación, fue la Constitución Política de 1998 la que introdujo este tipo de postulados por primera vez en la historia constitucional del país. Así, el Título III de la Constitución de 1998, que se refería a los "Derechos, Garantías y Deberes", incorporó un capítulo inicial denominado "Principios generales", los mismos que han sido desarrollados y ampliados en el actual texto constitucional.

En este contexto, para comprender adecuada e íntegramente los aspectos inherentes al ejercicio, interpretación y aplicación de los derechos, es necesario examinar cada uno de los principios que conforman esta categoría, puesto que estos mecanismos son un elemento fundamental para la materialización y exigibilidad de los derechos.

\section{LOS PRINCIPIOS COMO NORMAS JURÍDICAS}

Antes de estudiar cada uno de los principios de aplicación de los derechos reconocidos en la Constitución de la República, es necesario conocer qué tipo de normas son los principios y cuál es su finalidad en el ordenamiento jurídico, específicamente, en el texto constitucional.

La literatura jurídica sobre la teoría de las normas, se ha decantado por conceptualizar a los principios en base a sus rasgos distintivos que los diferencian de las reglas (Prieto Sanchís, 2014a, pág. 205), por lo que, para abordar y definir cada una de estas categorías normativas, conviene hacerlo en conjunto, esto es, analizando las características de ambos tipos de normas.

En este contexto, es importante señalar que los principios constituyen una clase singular de normas que, por su objeto jurídico y estructura, se diferencian sustancialmente de las reglas.

En cuanto a su objeto jurídico, los principios sirven de sustento de las reglas, es decir, constituyen postulados cuyo contenido se refleja y se 
desarrolla normativamente en el resto de preceptos jurídicos. Al respecto, Guastini (2014, págs. 184-189) se refiere a la condición "fundamental" de los principios, lo cual, desde su punto de vista, significa que estos enunciados otorgan sustento o justificación a otras normas, como las reglas; dicho de otro modo, los principios serían la base material sobre la cual se producen las reglas.

Por otra parte, los principios poseen una estructura indeterminada o abierta, en contraposición a las reglas, cuya composición se caracteriza por la presencia de una hipótesis o condición que, al verificarse, produce una consecuencia jurídica específica.

Aquellas características pueden ser complementadas para comprender de manera óptima la utilidad de los principios en el sistema normativo. El catedrático alemán Robert Alexy (2008, pág. 67) define a los principios como "mandatos de optimización", por cuanto, afirma que estas normas disponen una obligación que deberá cumplirse en la mayor medida posible, en atención a las condiciones jurídicas y reales de cada caso.

En este contexto, los principios no establecen una forma inequívoca, absoluta e incuestionable de alcanzar el objeto por el cual fueron previstos, sino que permiten una amplia gama de opciones, que tendrán que ser valoradas en cada circunstancia. Por ende, los principios deberán ser aplicados e interpretados en la medida que, en conjunto con el resto de principios y normas, permitan una solución óptima y armónica en cada situación.

A manera de ejemplo, el derecho a la libertad de opinión y expresión, tiene la finalidad esencial de permitir que cada individuo manifieste libremente su pensamiento y forma de concebir determinados aspectos, evitando que agentes externos limiten aquella potestad. Ahora bien, este derecho, por su condición de principio, tendrá un grado de materialización y protección dependiendo de la circunstancia en que se lo pretenda ejercer, ya que, si las expresiones vertidas por una persona versan sobre su gusto personal acerca de literatura o música, no es asimilable a si tienen como propósito disminuir la reputación de un tercero.

El mismo principio tendrá un alcance distinto para cada caso, puesto que, en la segunda situación, el principio en referencia riñe con el derecho a la honra y reputación, lo cual obligará a buscar una solución que satisfaga de manera equilibrada ambos principios, lo que se logrará mediante el libre flujo de ideas y expresiones siempre que no atenten contra el honor ajeno, es decir, a través de una interpretación del principio en función del contexto que lo rodea.

Por todo lo expuesto, los principios son las normas jurídicas fundamentales, indeterminadas, que carecen de una estructura hipotética, y 
que ofrecen un amplio margen de posibilidades para satisfacer el objeto por el cual fueron creadas. Aquella indeterminación y ambigüedad conlleva que su aplicación e interpretación en ocasiones no sea tan sencilla, por cuanto las consecuencias jurídicas no están expresamente individualizadas.

Por lo tanto, es de suma utilidad comprender adecuadamente la naturaleza jurídica, características y objeto de los principios, puesto que será su intérprete y ejecutor el que deba delimitar de la mejor manera su alcance y contenido, en función de las circunstancias que presente cada caso. Dicha importancia, evidentemente, se traslada también a los principios de aplicación, los cuales, como se verá a continuación, tienen ciertos matices que los diferencian de otros principios.

\section{PRINCIPIOS DE APLICACIÓN Y DERECHOS}

Otra de las clasificaciones tradicionales de las normas jurídicas, sugiere la existencia de preceptos sustantivos y adjetivos. Los primeros se refieren a aquellos enunciados que establecen derechos y obligaciones; mientras que, los segundos, regulan la forma en que se desarrollan los procedimientos (Simon, 2017, pág. 110); es decir, los postulados adjetivos determinan el funcionamiento de los medios para lograr la aplicación de las normas sustantivas.

Ahora bien, los principios de aplicación de los derechos no son normas adjetivas en su sentido puro y estricto, ya que, como se analizará más adelante, su contenido y alcance involucra también aspectos sustantivos; no obstante, la categorización antes señalada facilita la comprensión acerca de la función que desempeñan los principios de aplicación con relación a los principios constitucionales sustantivos, que en este caso se refieren a los derechos.

En este sentido, haciendo un símil, los principios de aplicación equivalen para los derechos, lo que, en teoría de las normas, las disposiciones jurídicas adjetivas a los preceptos sustantivos, por cuanto los primeros prevén un conjunto de pautas de interpretación y aplicación orientadas a que los derechos puedan ejercerse de una manera óptima y efectiva.

De ahí su valía y trascendencia en el sistema constitucional, pues actúan como un complemento de los derechos y son necesarios para satisfacer su pleno goce y ejercicio. 


\section{PRINCIPIOS DE APLICACIÓN DE LOS DERECHOS EN LA CONSTITUCIÓN ECUATORIANA}

Como ha quedado descrito, todos los principios que se examinarán a continuación, constituyen parámetros de interpretación y aplicación de los derechos, motivo por el cual, deben ser observados en cualquier escenario en que se discuta sobre el alcance o la pertinencia de los mismos.

Estos principios cuentan con un capítulo específico en la Constitución de la República; puntualmente, se encuentran reconocidos en sus arts. 10 y 11. A continuación se los estudiará.

\section{IV.1. Titularidad de los derechos}

La titularidad, en el ámbito jurídico, es la calidad que ostenta el destinatario de un precepto normativo, es decir, sobre quien recae un derecho o una obligación; en consecuencia, los titulares de los derechos constitucionales son todos los habilitados para ejercerlos.

Este aspecto ya fue regulado en la Constitución Política de 1998, cuyo art. 17, dentro de los denominados principios generales, establecía la obligación de que el Estado garantice el ejercicio de los derechos a todos sus habitantes. En este punto, es necesario precisar que dicho texto constitucional reconoció la existencia de derechos individuales y colectivos, es decir, se preveía una titularidad individual respecto de determinados derechos, pero además se consagraron otros de titularidad colectiva (cfr. Constitución Política de la República del Ecuador de 1998, Título III, capítulo 5).

De su parte, el art. 10 de la Constitución vigente, determina que «las personas, comunidades, pueblos, nacionalidades y colectivos son titulares y gozarán de los derechos garantizados en la Constitución y en los instrumentos internacionales. La naturaleza será sujeto de aquellos derechos que le reconozca la Constitución».

En este sentido, la regulación actual es más específica en detallar a los titulares de los derechos, por cuanto, si bien inicialmente se establece de manera general a las "personas", enseguida se puntualizan ciertos colectivos. Es importante señalar que el texto constitucional determina un conjunto de derechos colectivos, por lo que, para garantizar su pleno goce, corresponde reconocer su titularidad del modo que lo hace la Constitución. Al respecto, se puede afirmar que:

«No es nada obvio que los derechos humanos sólo puedan ser derechos atribuidos a personas o a sujetos individuales. Nada impide, en efecto, que también 
los grupos o sujetos colectivos puedan, en razón de determinados rasgos compartidos, tener pretensiones en torno a ciertos intereses o necesidades comunes (...)» (Pisarello \& Aparicio, 2008, pág. 146).

De este modo, de manera similar a lo que ocurría en la norma fundamental de 1998, en la Constitución vigente existe una dualidad en cuanto a la titularidad de los derechos, puesto que, las personas y los colectivos, están habilitados para el ejercicio los derechos correspondientes.

Ahora bien, un aspecto que innegablemente es novedoso no sólo en el país sino a nivel mundial, es la titularidad de derechos de la naturaleza. Sobre su justificación jurídica, se han desarrollado varios trabajos académicos con puntos de vista de diversa índole ${ }^{1}$. Independientemente de aquellas posturas, basta con señalar que la nueva concepción que sitúa a la naturaleza como titular de derechos, se fundamenta en una visión distinta a la antropocéntrica, la que consideraba al ser humano como objeto único de protección jurídica, autónomo e independiente del medio que lo rodea; en esta misma línea, cierto sector de la doctrina ha dicho que:

«La determinación de la naturaleza como sujeto de derechos, por su parte, responde a la teoría ecocéntrica, la cual coloca al ambiente y a la naturaleza como el eje central de las cuestiones ambientales. Esta corriente [...] establece que la especie humana es parte de la naturaleza y la vida depende del funcionamiento ininterrumpido de los sistemas naturales (...)» (Bedón, 2016, pág. 135).

En tal virtud, como principio rector de todo el sistema constitucional de protección de derechos, se prevé una titularidad amplia y sin restricción, dado que el constituyente, acorde con los principales instrumentos internacionales de derechos humanos ${ }^{2}$, reconoció a todas las personas y colectivos el goce de los derechos; por otro lado, de manera novedosa, se establecieron derechos de titularidad de la naturaleza, lo cual, desde mi punto de vista, está destinado a proteger al medio ambiente y, por ende, a las personas como parte de éste.

\section{IV.2. Exigibilidad de los derechos}

Este es un aspecto fundamental para el ejercicio de los derechos, puesto que la exigibilidad garantiza su cabal cumplimiento, en caso de ser

1 Cfr. Ávila Santamaría, Ramiro (2012). Los derechos y sus garantías. Quito: Corte Constitucional para el período de transición, págs. 111-149; y, Simon Campaña, Farith (2013). Derechos de la naturaleza: ¿innovación trascendental, retórica jurídica o proyecto político? Revista Iuris Dictio, 15, págs. 9-38.

${ }^{2}$ Cfr. Declaración Universal de Derechos Humanos, art. 1. Convención Americana sobre Derechos Humanos, art.1. 
anulados o menoscabados. De este modo, a través de la interposición de mecanismos y herramientas que procuran su pleno ejercicio, este elemento impide que los derechos se conviertan en simples declaraciones ineficaces.

La exigibilidad deviene, en términos generales, de la titularidad jurídica, por cuanto, quien ostenta una prerrogativa otorgada por un enunciado normativo, tiene la potestad de hacerla exigible frente a terceros. En este contexto, según la tradición normativa clásica, solo los titulares de los derechos son quienes pueden exigir su cumplimiento. Sin embargo, como se examinará a continuación, por tratarse de derechos, hay que tomar en cuenta ciertas particularidades que han sido advertidas en la jurisprudencia y en la doctrina.

El art. 11.1 de la Constitución establece la legitimación activa para exigir la materialización de los derechos; así, tal enunciado reconoce que «los derechos se podrán ejercer, promover y exigir de forma individual o colectiva (...)». Esta disposición debe ser leída en conjunto con el art. 86.1, que, dentro de las normas comunes de las garantías jurisdiccionales, establece «cualquier persona, grupo de personas, comunidad, pueblo o nacionalidad podrá proponer las acciones previstas en la Constitución».

En este sentido, a partir de las normas referidas, Ávila (2012, pág. 70) considera que el sistema constitucional configura una acción popular para proteger los derechos, lo que se traduce en una legitimación abierta para presentar las herramientas procesales que garantizan el ejercicio de los derechos, incluso los de titularidad de terceros.

Por su parte, otro sector de la doctrina ha expuesto que «la Constitución de 2008 se refiere a "cualquier persona" (art. 86.1), pero tampoco precisa si eso implica que la demanda se puede presentar por derechos propios o por derechos de terceros» (Aguilar, 2018, pág. 25).

Frente a esta discrepancia doctrinaria, la Corte Constitucional se ha referido acerca del contenido de los enunciados normativos citados previamente y ha determinado cómo ha de entenderse la legitimación activa para hacer exigibles los derechos a través de las garantías jurisdiccionales. Así, se ha determinado que:

«(...) toda persona, grupo de personas, pueblo o nacionalidad, está facultado para proponer o intentar una demanda de garantías jurisdiccionales sin ningún condicionamiento, en aras de asegurar o exigir la protección de derechos constitucionales. Ello es así, independientemente del interés o afectación directa que tenga o soporte el o la accionante sobre los hechos objeto de demanda, ya que los derechos constitucionales son objetivamente importantes, en tanto centro de la actuación estatal en el modelo que la Constitución proclama (...)» (sentencia 17017-SEP-CC, dictada dentro del caso 0273-14-EP). 
Por lo tanto, el sistema de protección de derechos en el país, a juicio de la Corte Constitucional, reconoce una legitimación activa abierta, a través de una acción popular; en función de aquello, el principio que establece el art. 11.1 de la Constitución de la República, habilitaría que las personas puedan proponer acciones tendientes a exigir el ejercicio de derechos, ya sea de titularidad propia o de terceros.

Cabe resaltar que la Constitución Política de 1998, en su art. 95, establecía que la acción de amparo podía ser propuesta por cualquier persona, por sus propios derechos o en representación de una colectividad. De tal manera que, la regulación actual, conforme el criterio de la Corte Constitucional, se diferencia sustancialmente de su antecesora, toda vez que establece una legitimación activa que trasciende del interés personal y admite la interposición de acciones para proteger y reparar derechos de terceros.

Esto implica que, a juicio de la Magistratura en mención, la visión tradicional acerca de la exigibilidad de derechos personales, no sea aplicable en materia de derechos constitucionales. Aspecto que no es compartido unánimemente por la literatura jurídica especializada; pero en este momento, por tratarse de un criterio jurisprudencial emitido por el máximo órgano de justicia constitucional, debe ser acatado por los operadores de justicia, autoridades públicas y ciudadanía en general.

\section{IV.3. Principio de igualdad y no discriminación}

La Constitución reconoce la igualdad como un derecho y, a su vez, como un principio de aplicación, por lo que se trata de un postulado que ha sido consagrado a partir de una dualidad. En este sentido, como principio sustantivo, se reconoce el «derecho a la igualdad formal, igualdad material y no discriminación» (art. 66.4); la norma establece el derecho como tal, desde su dimensión formal y material, según lo dice la Corte Constitucional:

«La primera (...) hace referencia a la igualdad ante la ley, es decir una igualdad en cuanto a la configuración y aplicación de normativa jurídica, mientras que la segunda hará referencia a las particularidades de los sujetos, grupos o colectivos, quienes deben ser tratados de manera igualitaria si se encuentran dentro de circunstancias fácticas similares, prohibiéndose cualquier acto discriminatorio (...)» (sentencia 0019-16-SIN-CC, caso 0090-15-IN).

Desde mi punto de vista, como principio de aplicación, la igualdad se traduce en el mandato constitucional que permite que las personas ejerzan todos sus derechos de manera equitativa y sin ser discriminados, conforme con el art. 11.2 del texto constitucional. Este principio es un eje transversal 
de todo el sistema de protección de derechos, que tiene por propósito garantizar que todas las personas gocen efectivamente de sus derechos, sin ser discriminadas.

Es importante resaltar que el art. 17 de la Constitución de 1998 señalaba que el Estado tenía que garantizar sin discriminación el eficaz ejercicio de los derechos. La redacción actual de este principio va más allá, pues, además identifica las denominadas categorías sospechosas y ordena la adopción de medidas de acción afirmativa, a fin de que todas las personas puedan gozar plenamente de sus derechos. En este orden de ideas, de la lectura de aquel principio, se desprende que su contenido abarca un mayor ámbito de especificidad, en comparación con la norma suprema anterior.

En lo concerniente a las categorías sospechosas, éstas constituyen una serie de criterios que no pueden justificar un tratamiento diferenciado, pues se presumirá que aquél es discriminatorio. La Corte Constitucional ha definido estas categorías como aquellas:

«(...) utilizadas para realizar tratos “diferentes” respecto de ciertos grupos o personas vulnerables que no resultan razonables y proporcionales, cuyo uso ha estado históricamente asociado a prácticas que colocan en situaciones de desventaja o desprotección a grupos de personas generalmente marginados (...)» (sentencia 080-13-SEP-CC, caso 0445-11-EP).

Mientras que, las acciones afirmativas se fundamentan en la dimensión material del derecho a la igualdad, que, como quedó señalado, promueve que todas las personas tengan igualdad de oportunidades y condiciones, lo cual, muchas veces requiere la adopción de medidas afirmativas por parte del Estado. Es decir, frente a situaciones específicas en las que no todas las personas partícipes estén en igualdad real, el Estado debe tomar ciertas «medidas de carácter temporal que, ante la existencia de desigualdades históricas, buscan acelerar el ejercicio de igualdad efectiva» (Salgado, 2006, pág. 172).

Al haberse previsto a la igualdad también como un principio de aplicación, a mi entender, no se disminuye o se niega que este atributo constituya un derecho sustancial. El texto constitucional debe ser leído e interpretado desde su integralidad y, precisamente, en su conjunto reconoce la dualidad de este derecho, lo cual lo complementa.

Por lo expresado, la Constitución otorga a la igualdad un carácter de principio general, para que su contenido sea observado de manera transversal en la aplicación e interpretación de todos los derechos. Desde mi punto de vista, la intención de aquello, radica en dotar de mayor fuerza a la materialización igualitaria del ejercicio de todos los derechos. 


\section{IV.4. Aplicación directa de los derechos}

Indudablemente, la revolución francesa fue un hito en el establecimiento del Estado de Derecho, antítesis del antiguo régimen caracterizado por el absolutismo. Entre sus postulados principales destacan la división de poderes y la soberanía nacional, mediante los cuales se delegó la soberanía a la nación, que fue representada por un parlamento.

En este contexto, al inicio los cuerpos constitucionales establecieron enunciados generales sobre el funcionamiento orgánico del Estado y reconocieron los derechos a los ciudadanos. El parlamento asumió un rol sustancial, pues representó la "voz" y "voluntad" del soberano y, bajo tal justificación, reguló aspectos más específicos y concretos a través de la ley.

Por tal razón, durante mucho tiempo se consideró que la constitución era un programa político y que la regulación jurídica concreta correspondía a la Ley, como expresión de la voluntad soberana. No obstante, el desarrollo del constitucionalismo ha dejado insubsistente aquella concepción, pues la fuerza normativa de la constitución se asocia indisolublemente a la idea del Estado Constitucional de Derecho, en el cual existen valores e intereses fundamentales previstos en un texto supremo que no pueden quedar supeditado a mayorías legislativas coyunturales.

En efecto, la constitución es la manifestación plena y pura del poder democrático plasmado en un acto constituyente, por lo que cuenta con legitimación democrática para organizar y limitar el poder (cfr. De Vega, 2011, pág. 18). Esta condición provoca su supremacía frente a cualquier otra manifestación jurídica y política, por lo que, sus disposiciones deben ser observadas y aplicadas en todo contexto.

Ahora bien, la doctrina jurídica tradicional afirma que la constitución contiene normas de directa aplicación, pero reconocía también otro tipo de disposiciones, denominadas programáticas (cfr. Sagüés, 1997, pág. 97). Esta clase de enunciados normativos, a decir de Ramiro Ávila, «(...) establecen objetivos a alcanzarse, tales como los derechos sociales, [que] solo pueden ser aplicadas si es que existe desarrollo normativo (...)» (2012, pág. 75). Tales normas programáticas son postulados generales que, para concretarse, requieren de regulación secundaria, por lo que su naturaleza jurídica es contraria al carácter o fuerza normativa de la constitución, más aún en relación con los derechos.

Una vez establecido el marco conceptual precedente, corresponde señalar que el art. 11.3 del texto constitucional vigente, prevé que «los derechos y garantías establecidos en la Constitución y en los instrumentos internacionales de derechos humanos serán de directa e inmediata aplicación (...). No podrá alegarse falta de norma jurídica para justificar su violación o 
desconocimiento» ${ }^{3}$. Por lo tanto, los derechos son de aplicación directa y, bajo ningún punto de vista, pueden ser concebidos como normas programáticas. Por lo tanto, no cabe justificarse su inobservancia o incumplimiento, en la falta de desarrollo normativo infra constitucional.

Además, el enunciado constitucional establece que todos los derechos son justiciables, lo cual, en mi opinión, contrasta con los sistemas constitucionales en los que únicamente puede exigirse de manera directa el cumplimiento de los derechos considerados fundamentales, categoría que no está prevista en la Constitución ecuatoriana pero que sí ocurre, por ejemplo, en la Constitución española ${ }^{4}$.

En consideración a lo señalado, todos los derechos son exigibles a través de los mecanismos respectivos, aspecto similar a lo que ocurría en el texto de 1998, puesto que la acción de amparo procedía para tutelar cualquier derecho constitucional ${ }^{5}$.

\section{VI.5. Principio de no restricción del contenido de los derechos}

$\mathrm{El}$ art. 11.4 de la Constitución establece que «ninguna norma jurídica podrá restringir el contenido de los derechos ni de las garantías constitucionales». Este principio debe ser comprendido en su real dimensión, pues es frecuente que se le otorgue un sentido que no tiene. Una cosa es que los derechos no pueden ser restringidos injustificadamente, y otra distinta es la posibilidad de hacer una regulación infra constitucional. Suele afirmarse, sin ningún tipo de reparo y de manera general, que los derechos no pueden ser restringidos y que, por tanto, cualquier condicionamiento, regulación o limitación a su contenido, estaría proscrita.

No obstante, no toda regulación es contraria a este principio, pues admitir aquello, significaría que todas las normas infra constitucionales, que se refieren al ejercicio de los derechos, vulneran el texto supremo, ya que éstas, en cierta medida, condicionan su contenido.

Como premisa fundamental, hay que tomar en cuenta que existe una corriente que considera que los derechos no son absolutos; inclusive, aquella literatura jurídica es clara en afirmar que poseen límites (cfr. Prieto Sanchís,

\footnotetext{
${ }^{3}$ De manera concordante, la Constitución Política de 1998 ya consagró este principio en el art. 18.

${ }^{4}$ En España no todos los derechos recogidos en la Constitución pueden ser tutelados a través del recurso de amparo constitucional, sino únicamente son los reconocidos en los arts. 14 al 29, más la objeción de conciencia prevista en el art. 30.

${ }^{5}$ Juan Pablo Aguilar (2018, pág. 27) expresa que el diseño normativo de la acción de amparo constitucional permitía proponer esta acción respecto de cualquier derecho; no obstante, añade que, en la práctica, aquello no ocurrió.
} 
2014b, pág. 217). Esta concepción ha sido acogida por la Corte Constitucional, que ha señalado que lo mencionado «(...) no implica que los derechos contenidos en la Constitución de la República son ilimitados o ilimitables, lo que comportaría calificarlos como absolutos frente a la premisa general de que no existen derechos absolutos (...)» (sentencia 00314-SIN-CC, casos 0014-13-IN y acumulados). Y en otro fallo afirmó:

«El principio de no restricción de derechos reconocido en el art. 11 numeral 4 , implica que estos no pueden ser disminuidos injustificadamente por el legislador u otros poderes públicos, lo cual no se opone a la tarea encomendada al legislador respecto de la configuración y regulación de derechos, que incluye el establecimiento de ciertos límites sustentados materialmente en principios constitucionales (...)» (sentencia 019-15-SIN-CC, caso 0030-11-IN).

Si bien la Corte admite la presencia de límites del contenido de los derechos, no acepta cualquier tipo de limitación, pues ésta deberá derivarse de la propia Constitución, o, como lo ha dicho la Magistratura, deberá justificarse «(...) en la necesidad de proteger o preservar no solo otros derechos constitucionales sino también otros bienes constitucionalmente protegidos (...)» (sentencia 003-14-SIN-CC, casos 0014-13-IN y acumulados). Bajo estas consideraciones, los derechos pueden ser desarrollados por la legislación secundaria; no obstante, aquella regulación no podrá disminuir injustificadamente su contenido y deberá permitir una satisfacción integral de la constitución y de todos los derechos y principios reconocidos en ella.

Otro aspecto por considerar es que todos los derechos tienen un contenido que no puede ser limitado o cercenado (cfr. Prieto Sanchís, 2014b, pág. 128). Por consiguiente, existe una clara diferenciación entre la regulación de un derecho, con la restricción de su contenido. Esto fue objeto de análisis del máximo órgano de control constitucional, que señaló:

«(...) la diferencia entre una limitación legítima y una restricción inconstitucional está determinada, entre otros aspectos, por el grado de invasión al derecho en cuestión. La violación al principio se configura al momento en que la limitación es tan aguda, que el derecho se vuelve irreconocible [...] por haber sido vaciado de su contenido, propósito o razón de ser (...)» (sentencia 002-18-SIN-CC, casos 0035-15-IN y acumulados).

En tal virtud, lo que reconoce el principio de aplicación objeto de análisis, según la jurisprudencia y la doctrina indicada, no es que los derechos no pueden ser limitados o regulados, sino que, su contenido no podrá ser vaciado o alterado de modo tal que sea irreconocible, pues aquello se torna en una restricción ilegítima a los derechos, que es inconstitucional. 
De este modo, el principio de no restricción conlleva que el desarrollo normativo respecto de un derecho debe realizarse bajo el criterio de proporcionalidad, sin que invadan la esfera esencial de los derechos. Así lo ha establecido la Corte Constitucional:

«(...) el estatus de protección que brindan los derechos reconocidos por la Norma Suprema no puede estar sujeto a limitaciones sin una justificación que esté basada en la satisfacción de otro derecho constitucional, y que se lo haga en razón de la proporcionalidad, sin llegar al extremo de desnaturalizar el contenido del derecho limitado (...)» (sentencia 006-15-SCN-CC, caso 0005-13-CN).

Por lo expresado, además del contenido esencial de los derechos, como límite de su regulación, se reconoce a la proporcionalidad como uno de los métodos para examinar la constitucionalidad de la limitación. Una medida legislativa será constitucional siempre que persiga la satisfacción de otro derecho y que su intervención sea equilibrada.

Por tanto, la proporcionalidad constituye un mecanismo idóneo para verificar si la restricción de derechos encuentra o no justificación de orden constitucional. Al respecto, Bernal Pulido ha afirmado que:

«(...) en el Estado constitucional no puede valer cualquier restricción a los derechos fundamentales sino sólo aquellas restricciones que sean: idóneas para contribuir a la obtención de cierto fin legítimo; necesarias, es decir, las más benignas entre todos los medios alternativos que gocen de por lo menos la misma idoneidad para conseguir la finalidad deseada; y proporcionales en sentido estricto, es decir, aquellas que logren un equilibrio entre los beneficios que su implementación representa y los perjuicios que ella produce (...)» (2008, pág. 82).

Vale añadir que la proporcionalidad ha sido recogida en la legislación ecuatoriana (cfr. Ley Orgánica de Garantías Jurisdiccionales y Control Constitucional, art. 3.2) como un mecanismo de interpretación constitucional, en términos similares a los delineados por la doctrina, por lo que constituye un método que debe ser empleado por los jueces constitucionales a la hora de analizar la constitucionalidad de actos normativos que limiten o regulen el contenido de los derechos.

El principio es de suma relevancia para el sistema constitucional de protección, pues impide una intervención normativa desproporcionada en el contenido de los derechos. El desarrollo jurisprudencial constitucional sobre la conceptualización del principio de proporcionalidad es acorde con la doctrina citada sobre el contenido esencial de los derechos.

El principio no es nuevo en el constitucionalismo ecuatoriano. Ya se encontraba previsto en la parte final del art. 18 de la Constitución Política de 1998. No obstante, tal enunciado condicionaba únicamente la tarea del 
legislador, pues se expresaba que la ley no podría restringir el ejercicio de los derechos, quedando excluidas el resto de normas jurídicas, lo cual a mi entender es corregido en el texto actual.

\section{IV.6. Principio de favorabilidad o pro homine}

El art. 11.5 de la Constitución establece el método de interpretación idóneo en materia de derechos y garantías. Se trata del principio de favorabilidad, también conocido como pro homine, el mismo que es ampliamente aceptado en varios sistemas regionales de protección de derechos y ha sido previsto en un sinnúmero de cuerpos constitucionales.

El art. 18 de la carta de 1998 ya contenía este recurso hermenéutico. $\mathrm{Su}$ redacción actual, sin embargo, precisa quiénes son los obligados a adecuar su accionar a este principio, puesto que determina que «en materia de derechos y garantías constitucionales, las servidoras y servidores públicos, administrativos o judiciales, deberán aplicar la norma y la interpretación que más favorezcan su efectiva vigencia». El principio procura satisfacer el ejercicio de los derechos, tanto en su aplicación como en su interpretación. Así lo ha reconocido la Corte Constitucional, cuya jurisprudencia expresa que:

«Tal principio supone que en caso de que hubiere dos normas aplicables para una misma situación y dos interpretaciones posibles para una misma norma, se ha de aplicar necesariamente aquella norma o interpretación que más favorezca efectivamente el ejercicio de derechos constitucionales. En tal sentido, cuando se trate de derechos, los jueces acudirán a la norma más amplia o a una interpretación normativa extensiva y por el contrario, cuando se trate de establecer límites al ejercicio de tales derechos, acudirán a la norma o a la interpretación menos restrictiva (...)» (sentencia 265-15-SEP-CC, caso 1204-12-EP).

Por consiguiente, este principio establece un postulado rector sustancial, que condiciona la aplicación e interpretación de los derechos, ya que obliga al poder público a efectuar un ejercicio hermenéutico de cada circunstancia, para decidir cómo interpretar o aplicar un derecho, debiendo siempre elegir lo que favorezca a un pleno y efectivo ejercicio del mismo.

\section{IV.7. Características de los derechos}

El art. 11.6 de la Constitución establece una serie de características aplicables para todos los derechos y sus principios. Es cierto que algunas de estas cualidades, como la irrenunciabilidad de los derechos, no son nuevas en el constitucionalismo ecuatoriano; no obstante, es novedoso que el constituyente haya recogido en este postulado todos los elementos que 
constan en la Declaración y Programa de Acción de Viena de 1993, dictada por la Asamblea General de las Naciones Unidas.

Las características señaladas en el texto constitucional determinan que los derechos son:

a) Inalienables. Según este elemento, en mi criterio, no se puede vulnerar ni restringir el contenido esencial de los derechos.

b) Irrenunciables. Las personas no pueden renunciar a la titularidad y a ejercer los derechos. Al respecto, el art. 15 de la Ley Orgánica de Garantías Jurisdiccionales y Control Constitucional permite desistir de acciones constitucionales, para lo cual, el solicitante deberá justificar que no existe renuncia de derechos, lo que en la práctica se torna bastante complicado, pues significa demostrar que los derechos cuya vulneración se alegó en la acción, no serán afectados al desistir de ésta.

c) Indivisibles. A mi entender, conforme esta característica, cada derecho es un todo, es decir, no se puede ejercer un derecho en parte y el resto no; asimismo, los derechos en su conjunto forman una unidad interrelacionada entre sí, por lo que «(...) no es posible separar a los derechos o considerarlos aisladamente (...)» (Salgado, 2012, pág. 73).

Ávila expresa que esta característica implica que «no se puede sacrificar un derecho a costa de otro» (2012, pág. 83), lo cual, a mi juicio, de aceptarse como cierto, significaría que mecanismos tales como la proporcionalidad y la ponderación, carecen de sustento constitucional y no son aplicables a los derechos. Considero que un derecho, en determinadas circunstancias, sí puede sacrificarse de manera equilibrada siempre que sea necesario para permitir un ejercicio más efectivo de otro derecho.

d) Interdependientes. Los derechos están vinculados entre sí, por lo que, una vulneración a un derecho podrá afectar a otros; de la misma manera, el ejercicio de un derecho, favorecerá la vigencia de otros.

e) De igual jerarquía. Este aspecto merece especial atención. La constitución vigente no categorizó a los derechos como de primera, segunda y tercera generación; por el contrario, se estableció una muy particular clasificación de derechos (v.gr. buen vivir, participación, naturaleza, pueblos y nacionalidades, libertad y protección). Una lectura integral evidencia que aquella categorización, sumado a la igualdad de jerarquía en los derechos, tuvo la intención de suprimir la noción de que ciertos derechos prevalecen sobre otros. Dicho de otro modo, lo que se buscó fue modificar la concepción que diferenciaba entre derechos fundamentales y derechos que no tenían aquella categoría.

Por lo tanto, la igualdad de jerarquía significa que, en abstracto, ningún derecho prima por sobre otro, por lo que los métodos para resolver conflictos entre derechos serán aplicables en virtud de las circunstancias concretas de 
cada controversia. Por ejemplo, en la ponderación no existe un peso abstracto a priori para cada derecho.

La Corte Constitucional se ha referido acerca del contenido de cada una de las características establecidas en el art. 11.6 de la Constitución de la República, del modo que sigue:

«Inalienables en el sentido de que los derechos constitucionales no pueden ser negados a ninguna persona; irrenunciables, por cuanto estos no pueden ser privados, ni su titular puede renunciar a ellos; indivisibles, en razón de que los derechos no pueden ser disgregados de los demás derechos, deben actuar todos de forma interdependiente, relacionados unos con otros, ya que son la base en la que se asienta el aparato estatal. Finalmente, nuestra Constitución de la República determina que los derechos constitucionales son de igual jerarquía y de aplicación directa, en el sentido de que todos tienen el mismo valor e importancia, y requieren la misma protección por parte del Estado, es decir, todos los derechos constitucionales, sin distinción alguna, son justiciables» (sentencia 146-14-SEP-CC, caso 1773-11-EP).

Por lo dicho, las cualidades antes detalladas deben ser observadas en la aplicación e interpretación de los principios sustanciales, puesto que delinean el contenido y los rasgos esenciales de los derechos, lo que incidirá en su pleno ejercicio.

\section{IV.8. Fuentes de los derechos}

La Constitución de la República establece las fuentes de los derechos al señalar que «el reconocimiento de los derechos y garantías establecidos en la Constitución y en los instrumentos internacionales de derechos humanos, no excluirá los demás derechos derivados de la dignidad de las personas» (art. 11.7). Así, el texto constitucional identifica las distintas esferas en las que constan los derechos, lo cual se preveía de modo similar en el art. 19 de la Constitución Política de 1998.

Los derechos no son considerados como tales a causa de su establecimiento positivo. La constitución y los instrumentos internacionales se limitan únicamente a reconocerlos, puesto que su existencia es un aspecto inherente a los seres humanos. En otras palabras, el origen de los derechos no se encuentra condicionado a que cierto cuerpo normativo lo determine así, pues su carácter es supra positivo y se fundamenta en nociones propias del ius naturalismo.

Al respecto, el profesor Hernán Salgado (2012, pág. 70) puntualiza:

«El desarrollo de la conciencia ética del ser humano ha permitido descubrir nuevos derechos que sustentan la dignidad humana. Lo expresado, conduce a pensar que, en un momento dado, ni la Constitución -por más perfecta que sea- ni los 
instrumentos internacionales pueden contener todos esos valores esenciales que son los derechos humanos, por ello es sensato proclamar que además de los derechos reconocidos y consagrados pueden existir otros (...)».

El origen primigenio de los derechos se basa en la dignidad, que, en palabras de Starck (2011, pág. 124), «(...) corresponde al ser humano concreto, rechazándose toda posibilidad de utilización del ser humano como simple medio para los fines de una sociedad organizada en forma colectiva o tecnocrática». La dignidad es una condición que deviene del ser humano, mediante la cual se busca un desarrollo integral de la persona, tanto desde un punto de vista individual como social, evitando su instrumentalización y menoscabo frente a intereses colectivos.

En consecuencia, la titularidad de los derechos no se agota en los reconocidos en la constitución, ni en los instrumentos internacionales de derechos humanos, sino que trasciende e incluye a todos los que se derivan de la dignidad humana, lo que la doctrina denomina la cláusula abierta para el reconocimiento de nuevos derechos.

De otra parte, si existen diferencias entre el contenido de un derecho reconocido al mismo tiempo en la constitución y en determinado instrumento internacional de derechos humanos, se deberá aplicar la norma que permita un ejercicio más adecuado del derecho.

Por tanto, considero que en materia de derechos no cabe usar el criterio de jerarquía normativa para establecer si la constitución prevalece sobre los instrumentos internacionales de derechos humanos o viceversa, pues más allá de aquella discusión, deberá efectuarse un análisis relacionado al contenido del derecho y dar prioridad al que más favorezca su plena vigencia.

Como corolario, los principios que constituyen el objeto del presente trabajo, son parámetros obligatorios de aplicación e interpretación de todos los derechos, sin importar su fuente de origen, es decir, si están reconocidos en la constitución, en instrumentos internacionales de derechos humanos o si devienen de la dignidad de las personas.

\section{IV.9. Principio del desarrollo progresivo y no regresividad de los derechos}

La Constitución vigente establece que «el contenido de los derechos se desarrollará de manera progresiva a través de las normas, la jurisprudencia y las políticas públicas» y que «será inconstitucional cualquier acción u omisión de carácter regresivo que disminuya, menoscabe o anule injustificadamente el ejercicio de los derechos» (art. 11.8).

Se puede afirmar que la Constitución reconoce dos principios vinculados entre sí. En primer lugar, el del desarrollo progresivo del 
contenido de los derechos, y, correlativamente, la prohibición de su regresión. La Corte Constitucional lo ha definido del siguiente modo:

«(...) los derechos constitucionales tienen tal importancia que una vez que han sido establecidos o consagrados en la Constitución o los Instrumentos Internacionales, no podrán ser disminuidos, desmejorados ni eliminados.

De este modo, la progresividad de los derechos constituye un mandato para los poderes públicos, en virtud del cual, ninguna ley, política pública, ni la jurisprudencia, podrán menoscabar un derecho previamente reconocido, ni privar a las personas de condiciones de protección adquiridas o colocarlas en condiciones de marginalidad y/o vulnerabilidad (...)» (sentencia 008-13-SIN-CC, caso 0029-11IN).

Ambos principios operan en conjunto, toda vez que se exige que los derechos sean desarrollados progresivamente, esto es, ampliando su margen y ámbito de protección, a la vez que se prohíbe un menoscabo o disminución de su contenido.

Es importante destacar que el texto constitucional establece una garantía normativa, en virtud de la cual «en ningún caso, la reforma de la Constitución, las leyes, otras normas jurídicas ni los actos del poder público atentarán contra los derechos (...)» (art. 84), lo que significa que, bajo ningún supuesto cabe una modificación normativa que disminuya el contenido de un derecho. Inclusive, la enmienda y la reforma de la constitución están proscritas en caso de que los cambios que se pretendan incluir signifiquen el menoscabo de los derechos reconocidos en el texto constitucional, en atención de las limitaciones materiales explícitas que constan en los arts. 441 y 442 de la Constitución (cfr. Polo, 2018, pág. 82).

De la misma manera, a pesar de que el poder constituyente es ilimitado positivamente, los derechos actúan como una limitación implícita en la expedición de una nueva constitución, por lo que no podrían ser eliminados o afectados en su contenido, ni siquiera en un acto constituyente (Oyarte, 2014, pág. 117).

Según el criterio de la Corte Constitucional, este principio cuenta con destinatarios específicos, pues condiciona a todos los órganos con competencia normativa, a quienes dictan políticas públicas y a los juzgados, tribunales y cortes que abordan los derechos a partir de su ejercicio jurisdiccional. Por tanto, todos estos deberán desarrollar progresivamente el contenido de los derechos, sin disminuirlo, anularlo o menoscabarlo.

\section{IV.10. El Estado frente a los derechos}

El art. 11.9 de la Constitución consagra un principio compuesto, que establece algunas obligaciones del Estado en materia de la protección de 
derechos. En primer lugar, se define el deber del Estado de "respetar" y "hacer respetar" los derechos. Si bien se podría pensar que se trata de una redundancia, ambas obligaciones son distintas y complementarias.

Al respecto, es importante recordar que el Estado de Derecho, en una primera etapa consagró los derechos civiles y políticos de las personas, asumiendo frente a ellos un rol de abstención. Dicho de otro modo, la manera de garantizar el goce de tales derechos era a través de la no injerencia en su ejercicio. En una segunda etapa surgieron otros derechos de distinta naturaleza jurídica, como son los económicos, sociales y culturales, respecto de los cuales se requería un rol activo e interventor del Estado.

Precisamente, el "respeto" a los derechos conlleva una obligación de abstención frente al adecuado ejercicio de los mismos. En tanto que, "hacer respetar", en referencia a los derechos, implica la necesidad de actuar positivamente para materializarlos (cfr. Ávila, 2012, pág. 91). Queda claro, entonces, que el rol del Estado ecuatoriano hacia la protección de los derechos tiene una doble función, dependiendo de cuál sea la naturaleza del derecho que debe precautelar.

Como segunda obligación, se establece la responsabilidad objetiva del Estado ante la violación de derechos, a causa de la falta o deficiente prestación de servicios públicos, o por las acciones u omisiones de funcionarios y servidores públicos, en el desempeño de sus cargos. Esto se traduce en que el Estado deberá hacerse responsable y reparar la afectación de derechos, provocada por cualquier persona que actúe en ejercicio de una potestad estatal.

En tercer lugar, de manera complementaria con el punto anterior, se establece el derecho a la repetición. A través de esta figura, el Estado debe investigar las circunstancias en que se provocó la vulneración de derechos, a fin de establecer las responsabilidades individuales correspondientes para que los valores destinados a la reparación, sean reintegrados al Estado. Sobre este mecanismo, la Corte Constitucional ha señalado que:

«(...) mediante este derecho se apropia a todas las personas que conforman la administración pública de la obligación constitucional de respetar y aplicar los derechos constitucionales, estando impedidos de efectuar acciones u omisiones que puedan menoscabar su efectivo goce, ya que en tal caso, serán directamente responsables por los daños que tal vulneración generó, [...] el derecho de repetición es ejercido por el Estado, a fin de establecer la responsabilidad del o los servidores públicos que en el ejercicio de sus funciones hubieren provocado la vulneración de derechos constitucionales» (sentencia 146-14-SEP-CC, caso 1773-11-EP).

En esta línea, la potestad de repetición debe ser leída integralmente con la responsabilidad objetiva del Estado, el mismo que está en la 
obligación de investigar los hechos que dieron lugar a la actuación lesiva de derechos, para determinar responsabilidades individuales. Esto, evidentemente, procura generar una cultura de respeto hacia los derechos, por cuanto, el menoscabo de ellos no terminará con la reparación del Estado, sino que quien lo causó debe devolver los gastos producto de la reparación, generando un efecto disuasivo. Ambas obligaciones estatales, se encontraban previstas en el art. 20 de la Constitución Política del año 1998.

Finalmente, el art. 11.9 puntualiza la responsabilidad objetiva del Estado y el derecho de repetición, en el ámbito específico del error judicial, detención arbitraria, retardo injustificado y, de manera general, inadecuada administración de justicia y violación de la tutela efectiva y debido proceso.

En definitiva, la actual constitución elevó al rango de principio de aplicación de todos los derechos, a las obligaciones que tiene el Estado con relación al manejo y protección de los mismos. Esto, en mi opinión, parece adecuado, ya que, en gran medida, se determinan las consecuencias jurídicas de la afectación de derechos, detallándose cómo debe repararlos el Estado.

La reparación de los derechos es un aspecto esencial para su materialización. Sin una reparación efectiva, la protección de los derechos pierde toda utilidad y resta eficacia normativa no sólo al texto constitucional, sino principalmente a estos bienes superiores denominados derechos.

Por lo tanto, el establecimiento de las reglas sobre la responsabilidad del Estado, forman parte fundamental para el ejercicio de los derechos, lo cual implica que sean aplicables en todo escenario en el que un derecho esté comprometido.

\section{CONCLUSIONES}

1. Cada tipo de norma cumple con una finalidad distinta en el ordenamiento jurídico. Los principios son aquellos enunciados que sirven como sustento material para el desarrollo de otra clase de preceptos normativos y plantean una amplia gama de opciones para la solución de una controversia, lo cual torna la labor de su intérprete en un aspecto que va más allá de la subsunción de una regla hipotética.

En efecto, por su estructura ambigua e indeterminada, el alcance de cada principio deberá ser establecido por quien lo interpreta y aplica, en función de las circunstancias fácticas y normativas específicas de cada caso.

Aquello reviste de suma importancia la labor de las autoridades públicas y judiciales frente a los derechos, pues serán responsables de interpretarlos y aplicarlos correctamente mediante un ejercicio 
hermenéutico minucioso que contemple todas las aristas y escenarios de cada derecho, en contraposición con las situaciones de hecho respectivas.

2. Precisamente, para asegurar aquella tarea, ésta debe ser guiada por un conjunto de postulados que orienten procedimental y materialmente el manejo, aplicación y garantía de los derechos.

Los principios de aplicación cumplen tal rol, pues constituyen un conjunto de preceptos que viabilizan la materialización de los derechos. Así, en el texto constitucional vigente, se reconocen pautas transversales de aplicación e interpretación que coadyuvan para una vigencia efectiva de los derechos. Por este motivo, si bien son preceptos de aplicación, su trascendencia es sustancial, por cuanto se convierten en una herramienta de concreción del fin máximo del Estado, esto es, la protección de los derechos constitucionales.

3. La Corte Constitucional del Ecuador, con virtudes y varios defectos, ha conceptualizado algunos de los principios de aplicación; incluso, en ciertas oportunidades, ha delineado su contenido a través de criterios doctrinarios, jurisprudencia de la Corte Interamericana de Derechos Humanos y otros estándares internacionales en esta materia. Sin embargo, es importante señalar que, por la ambigüedad e indeterminación de estos postulados, existirán no solo criterios doctrinarios opuestos, sino visiones distintas entre órganos jurisdiccionales nacionales e internacionales.

Frente a esta situación, los principios pro homine y de progresividad, cumplen un papel sustancial, toda vez que, cualquier nueva interpretación o alcance que se pretenda dar a los principios y derechos, tendrá que otorgar una mayor protección que la ya establecida. Por lo que, si una nueva conformación de la Corte Constitucional requiere alterar los contenidos ya fijados, deberá efectuar un ejercicio hermenéutico integral y propender a un mejor desarrollo de cada principio.

4. Hay que destacar que la correcta delimitación sobre el alcance de los principios de aplicación de los derechos, no es suficiente para que satisfagan el fin por el cual fueron establecidos. Estos preceptos de aplicación complementan la gama de derechos prevista en el texto supremo, por lo que, no basta su adecuada comprensión, sino que, es necesario que se los aplique efectivamente.

En razón de aquello, si bien es cierto que la Corte Constitucional ha dotado de contenido a estos principios en un sinnúmero de los casos que ha resuelto, su aplicación concreta no siempre ha sido consecuente con el alcance que otorgó a los mismos. Aquello deviene en una protección deficiente de los derechos, ya que, para su pleno ejercicio, estos requieren la observancia integral e irrestricta de todos los enunciados que disponen parámetros de interpretación y aplicación. 
5. Debatir acerca del contenido de cada principio, propiciará un espacio para desarrollar de mejor manera todos estos postulados de aplicación, lo cual, a su vez, se traducirá en que los derechos cuenten con un mejor marco normativo para su aplicación e interpretación.

En este trabajo, se ha brindado un panorama general acerca de los criterios jurisprudenciales desarrollados sobre varios de los principios de aplicación y las referencias doctrinarias relacionadas, para arribar a ciertas conclusiones muy particulares acerca del estado actual de estos principios. Como se ha indicado, aquello no representa de modo alguno la imposición de un pensamiento inequívoco de cómo deben entenderse estos postulados; por el contrario, a partir de esta base, la academia y los operadores de justicia deberán reflexionar acerca de los aspectos positivos y negativos que hoy son parte del contenido de cada principio de aplicación, para aportar y discutir nuevas alternativas tendientes hacia la consolidación de un Estado constitucional de Derecho, en el cual se respeten y garanticen los derechos. 


\section{REFERENCIAS}

Aguilar, J.P. (2018). El mito del nuevo paradigma constitucional. Quito: Instituto Iberoamericano de Derecho Constitucional, sección Ecuador.

Alexy, R. (2008). Teoría de los derechos fundamentales. Madrid: Centro de Estudios Políticos y Constitucionales.

Ávila Santamaría, R. (2012). Los derechos y sus garantías. Quito: Centro de Estudios y Difusión del Derecho Constitucional.

Bedón Garzón, R. (2016). Contenido y aplicación de los derechos de la naturaleza. Revista Ius Humani, 5, págs. 133-148.

Bernal Pulido, C. (2008). El Derecho de los derechos. Bogotá: Universidad Externado de Colombia.

Corte Constitucional del Ecuador. Sentencia 0019-16-SIN-CC, caso 0090-15-IN.

Corte Constitucional del Ecuador. Sentencia 002-18-SIN-CC, casos 0035-15-IN y acumulados.

Corte Constitucional del Ecuador. Sentencia 003-14-SIN-CC, casos 0014-13-IN y acumulados.

Corte Constitucional del Ecuador. Sentencia 006-15-SCN-CC, caso 0005-13-CN.

Corte Constitucional del Ecuador. Sentencia 008-13-SIN-CC, caso 0029-11-IN.

Corte Constitucional del Ecuador. Sentencia 080-13-SEP-CC, caso 0445-11-EP.

Corte Constitucional del Ecuador. Sentencia 146-14-SEP-CC, caso 1773-11-EP.

Corte Constitucional del Ecuador. Sentencia 170-17-SEP-CC, caso 0273-14-EP.

Corte Constitucional del Ecuador. Sentencia 265-15-SEP-CC, caso 1204-12-EP.

De Vega, P. (2011). La Reforma Constitucional y la problemática del poder constituyente. Madrid: Editorial Tecnos.

Ecuador (1998). Constitución Política del Ecuador (R.O. 1 de 11-XII-1998).

Ecuador (2008). Constitución de la República (R.O. 449 de 20-X-2008).

Ecuador (2009). Ley Orgánica de Garantías Jurisdiccionales y Control Constitucional (R.O. Supl. 52 de 22-X-2009).

Guastini, R. (2014). Interpretar y argumentar. Madrid: Centro de Estudios Políticos y Constitucionales.

Oyarte Martínez, R. (2014). Derecho Constitucional ecuatoriano y comparado. Quito: Corporación de Estudios y Publicaciones.

Pisarello, G. \& Aparicio Wilhelmi, M. (2008). Los derechos humanos y sus garantías, nociones básicas. Los derechos humanos en el siglo XXI: continuidad y cambios, págs. 139-162. 
Polo Pazmiño, E. (2018). El ámbito del control constitucional sobre la convocatoria a consulta popular en el Ecuador. Revista Ecuatoriana de Derecho Constitucional, II, 2, págs. 73-91.

Prieto Sanchís, L. (2014a). Apuntes de teoría del Derecho. Madrid: Editorial Trotta.

Prieto Sanchís, L. (2014b). Justicia Constitucional y Derechos Fundamentales. Madrid: Editorial Trotta.

Sagüés, N.P. (1997). Elementos de Derecho Constitucional. Buenos Aires: Ediar.

Salgado, H. (2012). Lecciones de Derecho Constitucional. Quito: Ediciones Legales.

Salgado, J. (2006). Género y derechos humanos. Revista Foro- Universidad Andina Simón Bolívar, 5, págs. 163-173.

Simon Campaña, F. (2013). Derechos de la naturaleza: ¿innovación trascendental, retórica jurídica o proyecto político? Revista Iuris Dictio, 15, págs. 9-38.

Simon Campaña, F. (2017). Introducción al Estudio del Derecho. Quito: Universidad San Francisco de Quito, Colegio de Jurisprudencia.

Starck, C. (2011). Jurisdicción Constitucional y Derechos Fundamentales. Madrid: Dykinson.

Tribunal Constitucional del Ecuador. Resolución 013-2004-TC. 